\title{
A Conference on Basic Research in Endocrine Dermatology
}

It is a great pleasure to present the Proceedings of the 3rd Teupitzer Colloquium 2000 which was dedicated to 'Basic Research in Endocrine Dermatology'. This nonprofit conference with limited participation, held in the marvellous lakeside Teupitz Castle Hotel, near Berlin on September 17-20, 2000, served as a forum to bring together 61 basic researchers and clinicians inside and outside Dermatology from 12 countries to discuss the newest and most relevant developments in this specific area of skin research. The scientific program included 30 communications, 21 lectures and 9 poster presentations, which were focused on (a) adrenal and gonadal hormones, (b) peroxisome proliferator-activated receptors, (c) immune-endocrine interactions, (d) natural retinoids and vitamin $\mathrm{D}$, and (e) genetics.

The dermatological research has experienced a rapid development in the last two decades, however, it has been rarely focused on the endocrine functions of the skin. It is only since a few years that clinicians and researchers in Dermatology started to initially explore skin as target tissue of the most hormones and later as the largest, endocrine, paracrine and autocrine organ of the body. The skin is able to metabolize steroid hormones and to produce derivatives with potentially systemic activity. Disorders of hormone metabolism can either induce direct effects on the skin or indirectly disturb skin homeostasis. Endocrine Dermatology is a new and exciting area of skin research whose scope includes skin diseases due to or associated with endocrine disorders, skin disorders which can be treated with hormones or with compounds with hormone-like activity, and skin disorders which occur as adverse events of hormone treatment or of treatment with compounds exhibiting a hormone-like activity.

This thematic issue includes 20 selected manuscripts presented by well-known experts that are representative of the scope and level of the 3rd Teupitzer Colloquium. They are addressed to clinicians and researchers, especially in the fields of Dermatology, Endocrinology, Gynaecology, Paediatrics, Genetics, Biology, Biochemistry, Pharmacology and Molecular Biology. I am grateful to all contributors for the quality of their papers and for making possible the presentation of this volume.

I want to express my sincere thanks to Prof. Michael B. Ranke, Thübingen, Germany, Editor-in-Chief of Hormone Research, and S. Karger AG and its staff who agreed to publish the Proceedings of the 3rd Teupitzer Colloquium 2000 as peer-reviewed papers under most favourable conditions.

I am pleased to acknowledge here the support of Galderma Laboratorium GmbH, Freiburg and Schering AG, Berlin, as well as of Merck \& Co., Inc., N.J., USA; Pfizer $\mathrm{GmbH}$, Karlsruhe; Pacific Corporation R \& D Center, Kyounggi-do, Korea; Galderma R + D, Valbonne, France, and Yamanouchi Pharma GmbH, Heidelberg to the 3rd Teupitzer Colloquium 2000.

Last but not least, I want to cordially thank Prof. Constantin E. Orfanos, Berlin for his continuous support, advice and encouragement and the colleagues of our Department for their contribution towards the success of the Colloquium.

Hoping that you will find the following articles interesting and stimulating, I wish you a pleasant lecture.

Christos C. Zouboulis, Berlin

\section{KARGER \\ (C) 2001 S. Karger AG, Basel \\ Fax + 41613061234 \\ E-Mail karger@karger.ch \\ www.karger.com \\ Accessible online at: \\ www. karger.com/journals/hre}

